\title{
Determination of various risk factors associated with acne vulgaris infection in Quetta, Pakistan
}

\author{
Faiz Ali ${ }^{1}$, Muhammad Shafi Hasni ${ }^{*}$, Shah Zain $\mathrm{Ali}^{3}$, Muhammad \\ Nadeem $^{2}$, Anwer Khan ${ }^{4}$ and Tehmina Mehak ${ }^{1}$ \\ 1. Bolan Medical College Quetta, Balochistan-Pakistan \\ 2. Department of Parasitology, Faculty of Veterinary Science, University of Agriculture, Faisalabad-Pakistan \\ 3. Institute of Microbiology, University of Agriculture, Faisalabad-Pakistan \\ 4. Institute of Physiology and pharmacology, University of Agriculture, Faisalabad-Pakistan \\ *Corresponding author's email: Shafi.hasni@gmail.com \\ Citation \\ Faiz Ali, Muhammad Shafi Hasni, Shah Zain Ali, Muhammad Nadeem, Anwer Khan and Tehmina Mehak. \\ Determination of various risk factors associated with acne vulgaris infection in Quetta, Pakistan. Pure and \\ Applied Biology. Vol. 8, Issue 3, pp1919-1924. http://dx.doi.org/10.19045/bspab.2019.80135
}

\begin{tabular}{llll}
\hline \hline Received: 26/12/2018 & Revised: 04/07/2019 & Accepted: 10/07/2019 & Online First: 17/07/2019 \\
\hline \hline
\end{tabular}

\section{Abstract}

Acne is a common skin disorder that affects both adolescents and adults. Epidemiological data on acne is limited from developing countries. The objective of present study was to investigate the prevalence and epidemiology of Acne vulgaris in humans in Quetta through a standardized questionnaire, which was prepared under the supervision of authentic skin specialist. One thousand subjects were examined and information was recorded in the questionnaire. The data was analyzed by applying statistical analysis (Minitab, Crosstab, Pearson Chi Square test and Analysis of Variance. The results of present study determined the prevalence of Acne vulgaris according to different variables including Age (Teenage, Adult), Gender (Male, Female), Skin (Dry, Normal, Oily, Semi Oily) Menstrual (Pre-menstrual, post-menstrual), Marital status (Married, Unmarried) and Food (Normal, Spicy) were found statistically associated $(\mathrm{P}<0.05)$ with the prevalence of Acne vulgaris in study area. The Chi-square test analysis indicated that acne vulgaris prevalence was significantly higher in teenagers, female, oily skin, pre-menstrual, unmarried and the individuals who consume more spicy food $(\mathrm{P}<0.05)$. The present study determined the current status of Acne vulgaris with association of different risk factors in population of Quetta. This study will be very helpful for its control program in district Quetta, Balochistan, Pakistan.

Keywords: Acne vulgaris; Propionebacterium acnes; Staphylococcus epidermidis; Quetta

\section{Introduction}

Acne vulgaris is a chronic inflammatory skin condition that affect different parts of body especially those parts that contain high number of oil glands, which includes face, neck, upper chest, shoulder and back generally acne appears before the onset of puberty [1]. The primary cause of acne is the hyperactive sebaceous glands. These glands are stimulated by the increased level of androgens, which are produced from adrenal glands, testes and ovaries in man and woman respectively [2]. While the secondary cause of acne are some commensal bacteria that includes; Staphylococcus epidermidis, Propionibacterium granulosum, Malassezia furfur and Propionibacterium acnes rapidly multiply during puberty and often lead tothe development of acne. Many 
researchers have worked on Propionibacterium acnes because it is a predominant organism in follicular flora [2, $3]$.

Teenagers are prone to acne more as compare to adults.80-90\% cases of acne are reported in teenagers. However, it is also reported pro and post adolescence in some individuals [4]. Acne can persist until the adulthood; in some cases it may regress spontaneously after the age of 20 ; in other case it may last longer and patient may suffer throughout their adulthood. Usually after the age of 25 , only $40 \%$ men and $54 \%$ women suffer from acne. According to recent studies, acne is reported to prevail in women $(9.8 \%)$ than that of men $(9.0 \%)$ of total population. The liability of acne decrease after the age of 40 to $1 \%$ in man while $5 \%$ in woman. The previous studies also showed that 650 million people i.e $9.4 \%$ of population were affected around the world with acne $[2,4]$.

The acne is a common skin disease that causes pimples, pustules, nodules, scars, cyst and scaly red skin. That are formed when hair follicles under the skin clog up due tothe retention of keratinocytes and oil from the skin [5]. Different factors are involved in the pathogenesis, Bacterial flora increases which alter the enzyme activity, retention of sebum in the Pilosebaceous follicle canal due to hyperkeratosis, increase in the sebaceous secretion and chemical alternation of sebum resulting increase free fatty acids [6, 7]. It is very interesting to know that these bacteria thrive best in anaerobic conditions; the atmosphere with low oxygen supply [8]. When follicle is blocked by blackhead, it provide a typical habitat for the growth often these bacteria. Under such optimal conditions bacteria are quick to split the triglycerides into fatty acids $[9,10]$. The distended follicle walls break and the contents (sebum, lipids, fatty acids, keratin and bacteria) enter the dermis, provoking an inflammatory and foreign body response (papule, pustule and nodule). Rupture plus intense inflammation lead to scars. Though it is not a life threatening disease but it should not be considered a trivial disease too, because it has adverse effect on individual social and psychological status $[11,12]$.

Acne vulgaris infection in humans in Pakistan however, is questionable to date. There is no data available about the factors associated with acne vulgaris in Pakistan. To study and investigate the factors associated with acne vulgarisa survey was conducted in Quetta district of Balochistan, Pakistan.

\section{Materials and methods}

This research work was planned to check the prevalence and epidemiology of acne vulgaris in Quetta Pakistan. The work plan comprised of three distinct phases.

The First phase included the preparation of questionnaire addressing different aspect of this disorder. The report was prepared under the supervision of skin specialists. On their suggestion different point were added to design a report related to acne vulgaris. The questionnaire contained eight parameters and all the parameters had close relation with this disease.

The Second phase was the survey phase. It was operated in outdoor patientsin Civil Hospital and Bolan Medical College Hospital in Quetta. The overall One Thousand cases of acne were interviewed and information was recorded in the predesigned questionnaire.

Then we progressed to the third phase which is statistical analysis; the data collected were analyzed statistically. All the different parameters were checked by Minitab, Crosstab, Pearson chi square test and ANOVA (Analysis of variance).

\section{Results}

The present investigation was conducted to determine the factors associated with Acne vulgaris in Quetta. The information was collected from Civil Hospital and Bolan Medical College Hospital (that are two main hospitals of the city). The duration of this study was six months, while aim of this study was to determine the factors associated with acne vulgaris in humans. 
The overall one thousand objects were investigated to determine the factors associated with acne vulgaris. The following factors were investigated and the information was collected.

The information was collected from different age groups like teenagers and young people. The results of different age groups were compared with each other. According to age wise distribution, it was observed that highest prevalence $(65 \%, \mathrm{CI}$, 60.5-70.8) was observed in teenagers as compare to (28\%, CI, 23.3-33.8) $\chi^{2}=12.74, P=0.013$ in adults. The other main factor of this study was to determine the prevalence according to gender wise. The highest prevalence (64\%, CI, 59.469.8) was examined in females as compare to $(48 \%, \quad \mathrm{CI}, \quad 44.6-53.9)$ $\chi^{2}=16.63, P=0.014$ males. Though the highest percentage of prevalence was reported in females but theseverity of clinical cases was more in males. Factor of marital status indicated highest prevalence (80\%, CI, 75.4-85.8) in unmarried population as compare to (20\%, CI, 15.425.2) $\quad \chi^{2}=1.24, P=0.016 \quad$ married population.

Good food results into good health. It was observed in current study that food hasdirect effect on the occurrence of acne vulgaris. The survey was conducted using human population. The interpretation was done between normal and spicy food consumers. In current study it was observed thatonly some people had aggravating effect of the food items however, mostof the people had no aggravating effect of the food items. Overall (72\%) people had no aggravating effect while highest prevalence (21\%, CI, 16.7-14.6) reported in spicy food consumers as compare to (9\%, CI, 4.5-14.6) $\chi^{2}=8.05, P=0.014$ normal food consumers.

Itwasfound that acne vulgaris was common in those females who had disturbed menstrual cycle as one of their major problem. This showed that females with irregular menstruation or any problem in menstrual cycle will also suffer from acne, as both are triggered by the activity of same hormone. In collected information, total $64 \%$ females were reported positive for acne vulgaris in which highest prevalence was observed (24\%, CI,19.7-29.8) in female involved in premenstrual flare as compared to $(14 \%, \quad \mathrm{CI}, \quad 9.5-19.8)$ $\chi^{2}=0.08, P=0.014$ postmenstrual flare. The results indicate that premenstrual and postmenstrual flare played a significant role in the acne vulgaris.

The type of skin is very important in case of acne vulgaris. This study results reported that high prevalence of acne vulgaris was observed in oily skin (70\%, CI, 65.5-75.6) followed in decreasing order by in normal skin (15\%, CI, 10.6-20.9) then semi oily skin (9\%, CI, 4.5-14.3) and dry skin type of the skin (6\%, CI, 1.8-11.2) $\chi^{2}=6.65, P=0.010$ both in male and females shown in (Table 1).

\section{Discussion}

The prevalence of acne vulgaris has been reported in different countries, while there prevalence rate according to factor and conditions vary from one country to another. A large study with 4,191 subjects was conducted in which prevalence rate of acne was reported $(68.5 \%)$ in boys and $(59.6 \%)$ in girls [13]. Prevalence rate from another study was $(20.8 \%)$ in girls and $(27.9 \%)$ in boys. The average rate of prevalence was reported 70 to $87 \%$ from all over the world neglecting the significant difference between countries $[1,14]$.

In present study different factors like, age groups, gender, marital status, menstrual status in girls, food type and skin type were studied. With respect to all age groups this study reported high rate $(65 \%)$ in teenagers as compare to other adult age groups, while $(68.5 \%)$ prevalence is also reported from other researchers. The reason for high rate of acne in children is due to hormonal changes that come with puberty. The main cause of acne is hormonal imbalance [2, 15].

According to gender base highest prevalence was observed in women (64\%) as compare to men (48\%). Results of this 
study were different as compare to other researchers because in other studies highest prevalence is reported in males as compare to females mentioned above [16].

Table 1. The Chi-Square test and ANOVA for predicting Acne vulgaris exposure in humans of Quetta, Balochistan, Pakistan

\begin{tabular}{|c|c|c|c|c|c|c|c|c|}
\hline Variables & Categories & $\begin{array}{c}\text { Total } \\
\text { Samples }\end{array}$ & Positive & Prevalence & $\begin{array}{c}95 \% \\
\text { Confidence } \\
\text { interval } \\
\end{array}$ & $\begin{array}{l}\text { Odds } \\
\text { Ratio } \\
\text { (OR) }\end{array}$ & $\begin{array}{l}\text { Chi- } \\
\text { Square }\end{array}$ & $P$ Value \\
\hline \multirow{2}{*}{ Age } & Teenage & 620 & 370 & 65 & $60.5-70.8$ & 0.284 & \multirow[b]{2}{*}{$X^{2}=12.7$} & \multirow[b]{2}{*}{$\mathrm{P}=0.013$} \\
\hline & Adult & 380 & 90 & 28 & $23.3-33.8$ & & & \\
\hline \multirow{2}{*}{ Gender } & Male & 440 & 216 & 48 & $44.6-53.9$ & 0.255 & \multirow[b]{2}{*}{$X^{2}=16.63$} & \multirow[b]{2}{*}{$P=0.04$} \\
\hline & Female & 510 & 302 & 64 & $59.4-69.8$ & & & \\
\hline \multirow{4}{*}{ Skin } & Dry & 235 & 10 & 6 & $1.8-11.2$ & 0.164 & \multirow{4}{*}{$X^{2}=6.65$} & \multirow{4}{*}{$\mathrm{P}=0.010$} \\
\hline & Normal & 190 & 20 & 15 & $10.6-20.9$ & 0.120 & & \\
\hline & Oily & 295 & 240 & 70 & $65.5-75.6$ & 0.132 & & \\
\hline & Semi Oily & 280 & 16 & 9 & $4.5-14.3$ & & & \\
\hline \multirow{2}{*}{ Menstrual } & $\begin{array}{c}\text { Pre- } \\
\text { menstrual }\end{array}$ & 310 & 177 & 24 & $19.7-29.8$ & 0.167 & \multirow{2}{*}{$\mathrm{X}^{2}=0.08$} & \multirow{2}{*}{$\mathrm{P}=0.014$} \\
\hline & $\begin{array}{c}\text { Post- } \\
\text { Menstrual }\end{array}$ & 250 & 35 & 14 & $9.5-19.8$ & & & \\
\hline \multirow{2}{*}{$\begin{array}{l}\text { Marital } \\
\text { Status }\end{array}$} & Married & 590 & 90 & 20 & $15.4-25.2$ & 0.158 & \multirow{2}{*}{$\mathrm{X}^{2}=1.24$} & \multirow{2}{*}{$\mathrm{P}=0.016$} \\
\hline & Unmarried & 410 & 350 & 80 & $75.4-85.8$ & & & \\
\hline \multirow{2}{*}{ Food } & Normal & 620 & 55 & 9 & $4.5-14.6$ & 0.040 & \multirow{2}{*}{$X^{2}=8.05$} & \multirow{2}{*}{$\mathrm{P}=0.014$} \\
\hline & Spicy & 380 & 80 & 21 & $16.7-26.5$ & & & \\
\hline
\end{tabular}

The food is very important to health, but it was observed in current study that food has affect on the acne vulgaris. The interpretation was done between normal and spicy food consumers. In current study, it was observed that some people had aggravating effects of the food items while majority people had no such effects of the food items. Overall (72\%) people had no aggravating effect while (28\%) people had the aggravating effect of the food items. The people affected by acne vulgaris due to aggravating effect of food, among them spicy food consumers more prevalent as compare to normal food consumer. In contrast to previous researchers who determined that diet has no effect on etiology of acne. While the current relationship status between acne and diet is under debate and not clear yet $[17,18]$.

It is also observed in present study results that pre-menstrual and post- menstrual flare play a significant role in Acne vulgaris. Current results are compatible with those who observed spots just before and during menstrual period in many girls and young women [19]. Acne vulgaris highest prevalence rate i.e. (70\%) was reported in people with oily skin as compared to other types of skin. According to current study results it reveals that oily skin is more prone to acne vulgaris. The oily skin is more prone to Acne vulgaris due to sebaceous (oil) glands present on skin which produce more sebum (oil) and make the skin oily is already described by [20].

The appearance of acne on face could lead to psychological problems which affect females more than that of males [16, 21]. The modified grading of lesion is observed as described by come done, papule, pustule, nodule and cyst $[22,23]$. This study results reported high prevalence of acne vulgaris from population of Quetta district. The more epidemiological studies should be conducted on large scale to estimate the acne vulgaris prevalence from all over the Pakistan.

\section{Conclusion}

Acne vulgaris is highly prevalent in Quetta, Balochistan, particularly in teenage females as compared to male. People with oily skin have more prevalence rate as compared to dry, normal and semi oily skin. In females, prevalence rate was higher during premenstrual stage as compared to post- 
menstrual stage. In unmarried individuals prevalence rate was higher as compared to married ones. People who eat spicy food have more prevalence rate as compared to people who eat normal food. On the other hand, this high prevalence is also highlighting the high risk of acne vulgaris in humans due to different factors. This was pilot study so further studies should be conducted on large scale to estimate all other factors associated with prevalence of acne vulgaris in Pakistan.

\section{Authors' contributions}

Conceived and designed the experiments: F Ali \& MS Hasni, Performed the experiments: F Ali \& T Mehak, Analyzed the data: M Nadeem, Contributed materials/ analysis/ tools: F Ali \& SZ Ali, Wrote the paper: SZ Ali \& MS Hasni.

\section{References}

1. Lynn DD, Umari T, Dunnick CA \& Dellavalle RP (2016). The epidemiology of acne vulgaris in late adolescence. Adole Heal Med Thera 19: 13-25.

2. Kilkenny M, Stathakis V, Hibbert ME, Patton G, Caust J \& Bowes G (1997). Acne in Victorian adolescents: associations with age, gender, puberty and psychiatric symptoms. J Paediat Child Health 33: 430-433.

3. Freyre EA, Rebaza RM, Sami DA \& Lozada CP (1998). The prevalence of facial acne in Peruvian adolescents and its relation to their ethnicity. $J$ Adolesc Health 22: 480-484.

4. Laczynski CM \&Cestari SC (2011). Prevalence of dermatosis in scholars in the region of ABC paulista. An Bras Dermatol 86: 469-76.

5. Stern RS (2000). Medication and medical service utilization for acne 1995-98. J Am Acad Dermato 43: 1042-1048.

6. Bowe WP, Joshi SS \& Shalita AR (2010). Diet and acne. J Am Acad Dermatol 63: 124-141.

7. Schafer T, Nienhaus A, Vieluf D, Berger J \& Ring J (2001). Epidemiology of acne in the general population: the risk of smoking. $\mathrm{Br} J$ Dermatol 145: 100-4.

8. Smith K \& Leyden JJ (2005). Safety of doxycycline and minocycline: a systematic review. Clinthera27: 13291342.

9. Strauss JS, Krowchuk DP, Leyden JJ, Lucky AW, Shalita AR \& Siegfried EC (2007). American Academy of Dermatology/American Academy of Dermatology Association. Guidelines of care for acne vulgaris management. J Am Acad Dermatol 56: 651-663.

10. Rosen T (2007). The Propionibacterium acnes genome: from the laboratory to the clinic $J$ Drugs Derm 6: 582-586.

11. Borgia F, Cannavò S, Guarneri F, Cannavò SP, Vaccaro M \& Guarneri B (2004) Correlation between endocrinological parameters and acne severity in adult women. Acta Derm Venereol 84: 201-204.

12. Wolff $\mathrm{K} \&$ Johnson RA (2009). Fitzpatrick's color atlas and synopsis of clinical dermatology. McGraw Hill.

13. Green D \& Friedman KJ (2001). Treatment of minocycline-induced cutaneous pigmentation with the Qswitched Alexandrite laser and a review of the literature. $J$ Amer Acad Derm 44: 342-347.

14. Choi YM \& Wu JJ (2015). Trends in the Frequency of Original Research in Acne Vulgaris, Rosacea, Dermatitis, Psoriasis, Skin Cancer, and Skin Infections. Perm J19: 44-56.

15. Uhlenhake E, Yentzer BA \& Feldman SR (2010). Acne vulgaris and depression: a retrospective examination. J Cos Derm9: 59-63.

16. Tan JK (2004). Psychosocial impact of acne vulgaris: evaluating the evidence. Skin Therapy Letter 9: 1-3

17. Davidovici BB \& Wolf R (2010). The role of diet in acne: facts and controversies. Clin Dermatol 28: 12 16. 
18. Collier N, Julie C, Harper C, Wendy $\mathrm{MD}$, Cantrell C, Wenquan G \& Foster W (2009). The prevalence of acne in adults 20 years and older. $J$ of the American Academy of Dermatol 58: 56-59.

19. Spencer EH, Ferdowsian HR \& Barnard ND (2009). Diet and acne: a review of the evidence. Inter $J$ Dermatol 48: 339-347.

20. Yentzer BA, Hick IJ, Reese EL, Uhas A, Feldman SR \& Balkrishnan R (2010). Acne vulgaris in the United States: a descriptive epidemiology. Cutis 86: 94-99.
21. Balaji A \& Thappa DM (2009). ProP le of acne vulgaris. A hospital-based study from south India. Indian $J$ Dermatol Venereol Leprol 75(3): 2728.

22. Utari A, Chonchaiya W, Rivera SM, Schneider A, Hagerman RJ, Faradz SM \& Nguyen DV (2010). Side effects of minocycline treatment in patients with fragile $\mathrm{X}$ syndrome and exploration of outcome measures. Amer $J$ inteldevt dis115: 433-443.

23. Williams C \& Layton AM (2006). Persistent acne in women. Amer $J$ Clinderm 7: 281-290. 